\title{
Ecotoxicological hazard assessment of deicing chemicals for higher plants
}

\author{
M.D. Fedorchenko ${ }^{1}, K . Y u$. Mikhaylichenko ${ }^{1 *}, O . V$. Ushakova $^{2}$, and I.A. Adarchenko ${ }^{1}$ \\ ${ }^{1}$ Peoples' Friendship University of Russia (RUDN University), Faculty of Ecology, 6 Miklukho- \\ Maklaya St, Moscow, 117198, Russian Federation \\ ${ }^{2}$ Center of Strategic Planning and Management of Medical and Biological Health Risks of the Russian \\ Federation, 119992, Pogodinskaya ul., 10s1, Moscow, Russia
}

\begin{abstract}
The article presents data on ecotoxicological hazard assessment of different types of deicing chemicals for higher plants. The assessment was carried out according to a specifically developed rapid test on oats seeds. The phytoeffect was determined by comparing the lengths of the seedling roots placed in a solution of deicing chemicals and was calculated by the effect size of root growth inhibition comparing with proof sample. The safest composition of deicing chemicals was determined.
\end{abstract}

\section{Introduction}

Currently, many cities use deicing chemicals (hereinafter - PGR) during the cold period to reduce slip effect. However, despite the undoubted benefit, deicing chemicals have immediate as well as delayed effects on the environment and on human health $[1,2]$.

In this regard an experimental study was conducted of the effect of different types of PGR on seed germination oats. The study was conducted from July $1^{\text {st }}$ to August $1^{\text {st }}$ of 2019 at the laboratory for environmental and hygienic assessment of soil and waste of the Center for Strategic Planning and Management of Medical and Biological Health Risks of the Ministry of Health of the Russian Federation with the guidance of Savostikova O.N. [3].

\section{Methodology}

The phytotoxic properties of PGR were evaluated using the rapid test on oats in accordance with the current method: Guidelines. MR 2.1.7.2297-07: Justification of production and consumption waste hazard class according to phytotoxicity [4]. According to the results of preliminary studies oat seeds was the most stable and gave the most reproducible data compared to seeds of other crops (peas, cucumbers, wheat, carrots, etc.) in this regard they were chosen for the present study [3].

\footnotetext{
*Corresponding author: mikhaylichenko-kyu@ rudn.ru
} 


\section{Results and discussion}

Three types of deicing chemicals were selected for analysis: PGR 1 containing $80 \% \mathrm{NaCl}$ and $20 \% \mathrm{CaCl}_{2}$; PGR 2 containing $72 \% \mathrm{NaCl}, 17 \% \mathrm{CaCl}_{2}$, and $11 \% \mathrm{HCO}_{2} \mathrm{Na}$ - sodium formate; and PGR 3, which includes $35 \%$ sodium chloride, $50 \% \mathrm{CaCl}_{2}$, and $15 \% \mathrm{HCO}_{2} \mathrm{Na}$. A solution with a PGR concentration of $100 \mathrm{~g} / \mathrm{L}$ was prepared from each sample. Distilled water was used as for proof sample. Also, we used compositions with different PGR obtained by sequential dilution of the initial solution by 10,100 , and 1000 times $[5,6]$.

Seeds were germinated on filter paper in petri dishes for 7 days in dark conditions at a temperature of $\mathrm{t}=25 \pm 2{ }^{\circ} \mathrm{C}$. The phytotoxic effect was evaluated by the magnitude of the inhibition of root growth relative to the proof sample (Phytoeffect,\%) [3]. A proof sample, initial solution and all dilutions were analyzed in threes petri dishes for each one [4]. In each cup there were placed 25 dry healthy seeds with germination rate at least $95 \%$.

After that, the root lengths of the germinated seeds were measured, and their average lengths in the proof and experimental samples in each repetition were calculated according to the formula (1):

$$
\mathrm{L}_{\mathrm{av}}=\Sigma \mathrm{L}_{\mathrm{i}} / \mathrm{n}
$$

where $L_{i}$ - the length of the maximum root of each seed (мм); $n$ - total number of analyzed seeds [5].

Based on the obtained results, the general average values of root lengths were calculated. Their values are given in table 1 .

Table 1. The results of the average root lengths of the proof and experimental samples.

\begin{tabular}{|c|c|c|c|c|c|}
\hline \multirow{2}{*}{$\begin{array}{c}\text { Type } \\
\text { of } \\
\text { PGR }\end{array}$} & Sample & \multicolumn{3}{|c|}{$\begin{array}{c}\text { Average root lenth, } \\
\text { Lav }\end{array}$} & \multirow{2}{*}{$\begin{array}{c}\text { Overall average, } \\
\text { Lov, mm }\end{array}$} \\
\cline { 2 - 5 } & & 1 & 2 & 3 & \\
\hline \multirow{4}{*}{ PGR1 } & Proof sample & 91.19 & 73.64 & 74.35 & 79.70 \\
\cline { 2 - 5 } & Primary solution & 0.00 & 0.00 & 0.00 & 0.00 \\
\cline { 2 - 5 } & Delution R 10 & 21.76 & 11.61 & 13.50 & 15.62 \\
\cline { 2 - 5 } & Delution R 100 & 63.29 & 86.04 & 83.91 & 77.75 \\
\cline { 2 - 5 } & Delution R 1000 & 83.61 & 84.48 & 85.64 & 84.58 \\
\hline \multirow{4}{*}{ PGR2 } & Proof sample & 72.04 & 56.80 & 68.31 & 65.72 \\
\cline { 2 - 5 } & Primary solution & 0.00 & 0.00 & 0.00 & 0.00 \\
\cline { 2 - 5 } & Delution R 10 & 5.29 & 12.13 & 12.86 & 10.09 \\
\cline { 2 - 5 } & Delution R 100 & 76.48 & 67.12 & 69.55 & 71.05 \\
\cline { 2 - 5 } & Delution R 1000 & 84.13 & 81.83 & 86.52 & 84.16 \\
\cline { 2 - 5 } & Proof sample & 79.96 & 80.12 & 75.81 & 78.63 \\
\cline { 2 - 5 } & Primary solution & 0.00 & 0.00 & 0.00 & 0.00 \\
\cline { 2 - 5 } & Delution R 10 & 11.79 & 21.25 & 15.08 & 16.04 \\
\cline { 2 - 5 } & Delution R 100 & 85.42 & 77.21 & 81.72 & 81.45 \\
\cline { 2 - 5 } & Delution R 1000 & 86.72 & 90.24 & 94.48 & 90.48 \\
\hline
\end{tabular}

If the total average length of the seed roots germinated in solutions is greater than (or equal) to the total average length of the seed roots germinated in distilled water, then there is no adverse effect of the PGR solution.

Using the obtained values of the total average root lengths, the values of the inhibition effect for each PGR solution were calculated using the following formula (2):

$$
\mathrm{E}_{\text {inh }}=\left(\left(\mathrm{L}_{\mathrm{p}}-\mathrm{L}_{\mathrm{ex}}\right) / \mathrm{L}_{\mathrm{p}}\right) \times 100
$$

where $\mathrm{E}_{\mathrm{inh}}$ - inhibition effect (\%); $\mathrm{L}_{\mathrm{ex}}$ - average root length in the experiment $(\mathrm{mm}) ; \mathrm{L}_{\mathrm{p}}$ - average root length in proof samples $(\mathrm{mm})$. 
Based on the calculation results, a graph of the dependences of the phytoeffect on the dilution of PGR (Fig. 1).
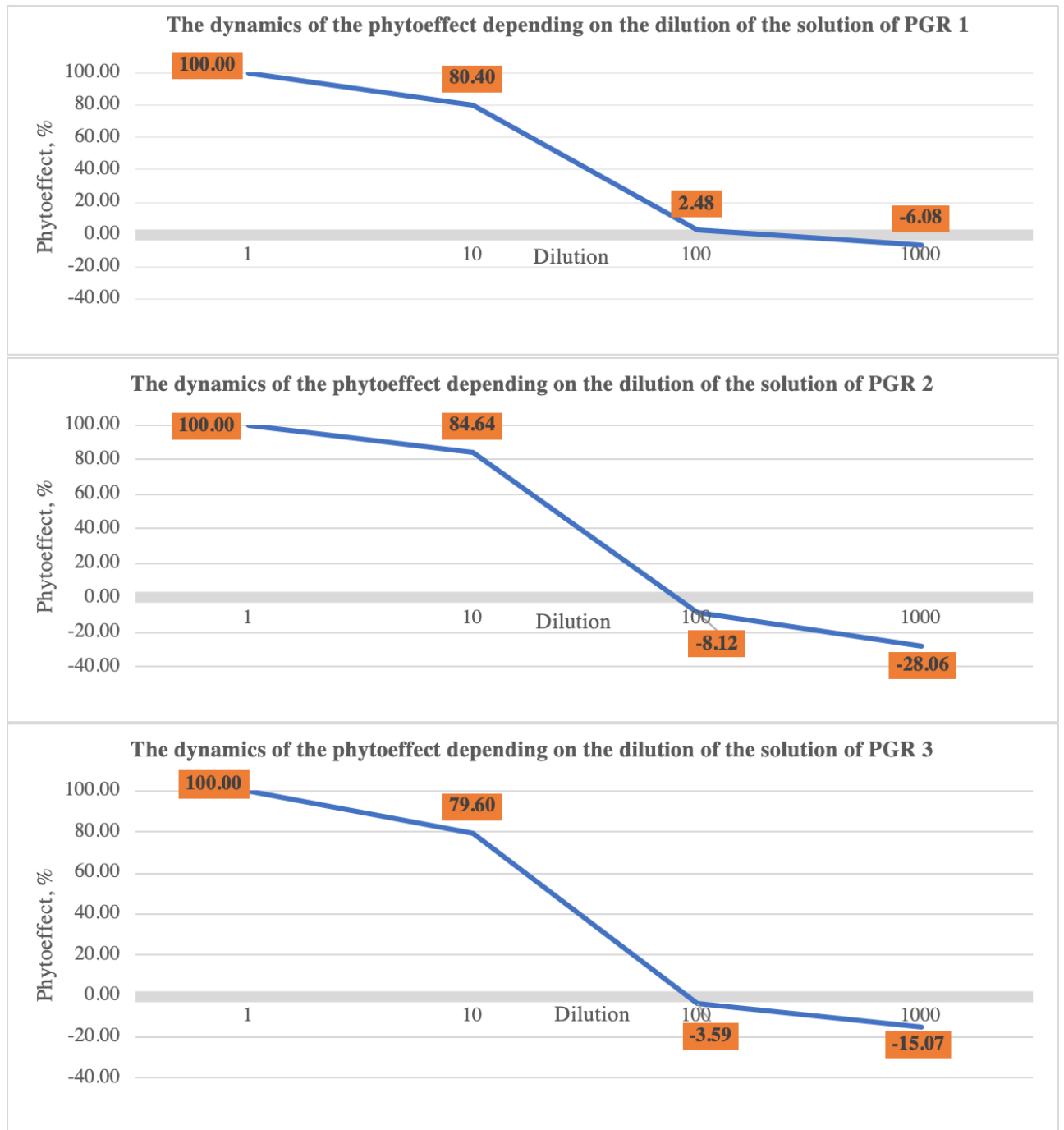

Fig. 1. The dynamics of the phytoeffect depending on the dilution of the solution of PGR.

As figure shows the complete absence of a negative phytoeffect is observed only in diluting the PGR solution more than 100 times.

After conducting a regression analysis of the graph, we simulated a straightforward relationship between dilutions of PGR solutions and the magnitude of the toxic effect (dependence of $\mathrm{LgR}$ on $\mathrm{E}_{\mathrm{inh}}$ ). As a result, the equations of the regression model were derived, based on which a coefficient was obtained corresponding to each phytoeffect value and a regression coefficient for each type of PGR. According to formula (3), threshold dilutions of LimR (dilutions causing a phytoeffect at the level of $20 \%$. The phytotoxicity threshold assumes that dilutions of the PGR solution exceeding its value will be safe for the growth and development of higher plants) were calculated:

$$
\operatorname{LgR}=\left(-\mathrm{m} \times \mathrm{E}_{\text {inh }}\right)+\mathrm{b}
$$


Table 2. The threshold dilutions of the studied deicing chemicals.

\begin{tabular}{|c|c|c|}
\hline Type of PGR & $\begin{array}{c}\text { Threshold dilution } \\
\text { LimR }_{\mathbf{2 0}}\end{array}$ & $\begin{array}{c}\text { Threshold concentration } \\
\text { LimC } \mathbf{2 0}, \mathbf{g} / \mathbf{L}\end{array}$ \\
\hline PGR1 & 113 & 0.9 \\
\hline PGR2 & 67 & 1.5 \\
\hline PGR3 & 85 & 1.2 \\
\hline
\end{tabular}

Therefore, as a result of the studies, it was found that all analyzed samples of PGR are highly phytotoxic. Thus, for the purpose of recommending the safe use of the studied deicing chemicals, it should be noted that dilution of the initial solutions $(100 \mathrm{~g} / \mathrm{l}) 113$ times $(0.9 \mathrm{~g} / \mathrm{l})$ for PGR 1, 67 times (1.5 g/l) for PGR 2 and 85 times (1.2 g/l) for PGR 3 are safe for seed germination of higher plants. For all dilution values lesser than indicated, phytotoxicity should be expected [5]. PGR 2 has the smallest phytotoxicity.

\section{Conclusion}

As a result of the rapid test on oat seeds and subsequent calculations, it was found that all analyzed samples of PGR have high phytotoxicity.

The adverse effect of PGR terminates only if the initial solution $(100 \mathrm{~g} / \mathrm{l})$ is subjected to strong dilution. The largest dilution of $100 \mathrm{~g} / \mathrm{l}$ solutions is required for PGR1 (113 times), the smallest is for PGR2 (67 times).

\section{References}

1. S.B. Chudakova, Dis. ... cand. medic. Sciences, Toxicological and hygienic assessment of the degree of danger of anti-ice reagents, 202, (2006) (in Russian).

2. A.I. Kurbatova, K.Y. Mikhaylichenko, A.Y. Dorontsova, IOP Conf. Ser.: Earth Environ. Sci., 272, 7, (2019).

3. M.A.Vodyanova, O.V. Ushakova, L.G. Donerjan, I.S. Evseeva. Modern problems of science and education, 5, 10, (2018) (in Russian).

4. Guidelines. MR 2.1.7.2297-07. Justification of production and consumption waste hazard class according to phytotoxicity, 15, (2018) (in Russian).

5. V.A. Korolev, A.K. Gornyakov. Engineering survey, 12, 9, (2018) (in Russian).

6. A.V. Sbitnev, M.A. Vodianova, I.A. Kriatov, L.G. Donerian, I.S. Evseeva, O.V. Ushakova, D. I. Ushakov, I.S. Matveeva, O.M. Rodionova, Hygiene and Sanitation, 95(8), 5, (2016) (in Russian). 